\title{
Impact of Renewable Distributed Generation on Protection Coordination of Distribution System
}

\author{
Mahesh Dahal, Ajay Kumar Jha, Rudra Mani Ghimire
}

\begin{abstract}
This paper presents a study on protection coordination of protective devices in a radial distribution system by considering penetration of distributed generation. This paper presents the study of protection coordination among various protective devices without and with penetration of DGs in distribution network. The proposed approach is tested on modified IEEE 13 Bus radial distribution system. When fault occurs in the system, level of fault current changes which in turn changes the operating time of various overcurrent relays. Therefore, it is essential to calculate and recommend method of the relay setting so as to minimize the operating time of relays and also to avoid its mal-operation. In this paper, the protection scheme is optimally developed by taking into consideration the above mentioned circumstances. The operating time of relays can be reduced and, simultaneously, coordination can be maintained by considering the optimum values of time dial setting (TDS). The proposed method used the Genetic Algorithm (GA) for determining the optimum values of TDS of overcurrent relays and hence operating time of circuit breaker $\mathrm{CB}$.
\end{abstract}

Index Terms - Distributed Generation, Protection Coordination, Renewable Energy, Distribution System, Genetic Algorithm.

\section{INTRODUCTION}

For so many years, the only way to supply consumers with electricity was to transmit electrical power from power generation plants via transmission lines to distribution networks. There were always chances of short circuits occurring at the generation, transmission or distribution networks. In order to limit the damage which could be caused by such short circuits, protection zones were set using relay-controlled circuit breakers $(\mathrm{CB})$ and fuses. Protection zones were made from at least one primary and one backup circuit breaker. The backup circuit breaker was a primary circuit breaker in another protection zone and was backed up by another breaker and so on. The relay coordination is necessary in order to check unnecessary tripping of the CBs causing more consumers to loose supply, unless the primary relays fail to trip.

Later, Distribution Generation (DG) was introduced; they are decentralized, modular and more flexible power generation and they are usually located close to the load they serve. They also have relatively small generation power. The protection and relay coordination between the primary and the backup when DGs are integrated with the main grid is a

Mahesh Dahal, Dept. of Mechanical Engineering, Institute of Engineering, Pulchowk Campus, Tribhuvan University, Pulchowk, Lalitpur, Nepal, +977-9841485062

Ajay Kumar Jha, Dept. of Mechanical Engineering, Institute of Engineering, Pulchowk Campus, Tribhuvan University, Pulchowk, Lalitpur, Nepal, +977-9841323147

Rudra Mani Ghimire, Dept. of Mechanical Engineering, Institute of Engineering, Pulchowk Campus, Tribhuvan University, Pulchowk, Lalitpur, Nepal, +977-9851139295 challenge is even harder when the percentage of DG generated power is getting higher in comparison to the loads connected to the grid [1]. This thesis looks at such challenges with some case studies in IEEE-13 Bus distribution network.

It is a common practice worldwide to connect distributed generators (DG) by means of solar, wind, biomass, and other sources to distribution systems. The DGs could provide diversity, redundancy and security. Meanwhile, they could also cause reliability and power quality problems too. Given significant level of integration; it is essential to revise the operation, protection and control of distribution systems in accordance to the emergence of distributed generation. The previous studies have shown that distributed generation caused several challenges to the protection of distribution networks such as false tripping in feeders, nuisance tripping of production units, protection blinding, changes of fault levels, unintended islanding, and prohibition of automatic reclosing. The appearance and impact of these problems depend on both the characteristics of DGs and distribution network [7]. In general, the impact depends on penetration level of DGs and connection point in distribution network, as well as generation technology. Regardless of the impact, it is necessary for electric utility to revise protection coordination to maintain standard of connection. The good standard may be measured in terms of accurate and on-time detection, reliability and dependability, as well as equipment costs

The incentives introduced by Governments and the rapid reduction in the manufacturing and installation of renewable energy resources (RES) like wind and solar would equally accelerate the heavy penetration. This would impact on relay operation and coordination in existing protection of the distribution system. These complications need urgent attention in the form of extensive study and simulations so that reliability and the gains of the DG could be achieved.

Over the past years, distribution system (DS) had been passive at the receiving end of the power system. There were few protection elements like fuses protecting the distribution transformers, sectionalizers, automatic reclosers, protecting the main distribution lines and circuit breakers at the injection substations. The problems in coordinating these protection elements were few, the major ones were the relays located at the injection substations. The introduction of distributed generation (DG) has immediately brought the challenges of so many issues like power quality, fault calculation, network stability, power factor corrections, power filter optimizations, etc [2]. However, one of the most important impacts of DG on power distribution system (DS), which is impact on protection system was rarely investigated academically and most of the carried out relay coordination in DS were mainly based on engineers' experience in the field with very little evidence of a solid academic investigation of how the relay coordination could be carried out. It was obvious that usual relay protection is not fit for purpose particularly at high percentage 
penetration level of DS. This topic has been worked upon by many researchers and the challenge was mainly on how to design a complete protection system at distribution level for system incorporating renewable energy systems.

Protection planning in the DS was simple, with few instruments, like over current relay (OCR) in the substation, reclosers in the middle of the circuit and fuses at the branch-offs/distribution transformers. Relay coordination was done by measuring the minimum fault current (Imin) and the maximum fault current (Imax) and making sure fault currents passing through these protective instruments do not fall outside these limits, as the flow of current is one direction only. The new method of interconnecting the Distribution generation (DG) to the DS has complicated the whole PQ and Protection problems. High penetration of DG especially the renewable energy resources (RES) types are on the increase in the distribution circuits. This has made RES or green energy as it is called to become the bedrock of research. It is important to study and analyze how high can the penetration be, $20 \%, 100 \%$ of the feeder load before the protection coordination and power quality issues become major problems. The new technical problems that will come up using distributed generation should be studied deeply. The impact on the Power Grid supply due to large number of rooftop solar when it becomes the main power producer should be analyzed. Protection coordination challenges that could be brought by these changes is the motivation for this project. The RES are intermittent and the load are variable, impact of these two variables on the reliability of the Distribution supply system should be observed. The very challenging issue of proper placement of DG in the distribution circuits for obtaining maximum potential benefits would need more research, as DGs could be privately or utility owned. The rapid design and manufacturing development of the RES equipment is currently on the increase, scientific developments to improve their use, their future prospects and their development motivates this research.

\section{METHODOLOGY}

\section{A. Modeling of Distribution System}

The distributed generation is increasing day by day and mostly it is connected at lower voltage level, i.e. distribution system. Most of the distributed system is in radial distribution network. In this thesis, the IEEE 13 Bus radial distribution system is used as test network for obtaining the objective of this thesis. Standard IEEE 13 Node Test Feeder [3] has the thirteen numbers of buses as shown in figure 1 .

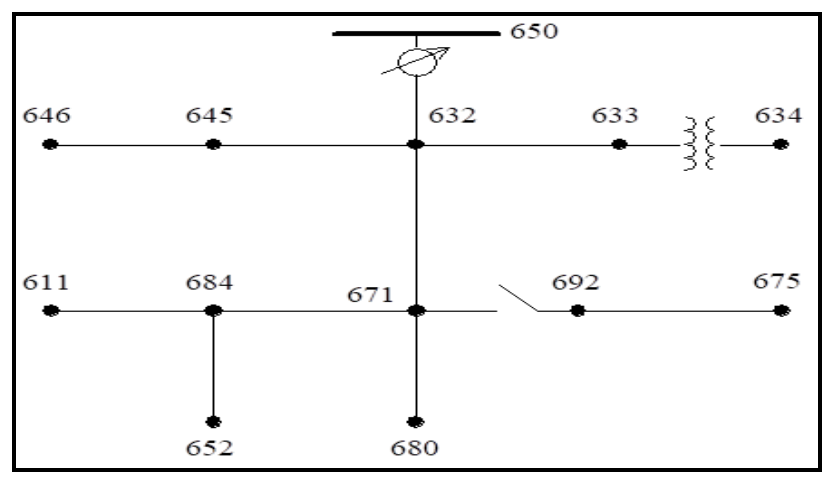

Fig. 1. IEEE 13 Node Test Feeder
IEEE 13 Bus is created in the ETAP and MATLAB software for the simulation purpose. The verification of this developed bus system is done according to the IEEE Distribution System Analysis Subcommittee. To model the distribution IEEE thirteen-bus system, an equivalent network was designed in ETAP with the following assumptions:

- The uniformly distributed load is modeled using two lumped loads at both end of terminals.

- The single phase load of constant current is modeled using fairly accurate lumped load.

\section{B. Load Flow and Short-circuit Analysis}

The verified IEEE bus is then tested in different condition of the electrical parameters. The detail unbalance load flow study is done in this developed network and the result of load flow analysis is compare with Distribution System Analysis Subcommittee numbers. Then the thus developed model is modified in order to analyze the behavior of the system with different loading condition. The load is varied in different buses at different time frame and the data is observed from different branches. Thus obtained records are studied to obtain the behavior of the system at different loading condition.

After the load flow study of the above mention bus system, Short-circuit analysis is done in this system. Short-circuit condition is created at different branches and buses of the system and the performance of the system with this short-circuit condition is observed. After observation of load flow examination and short-circuit analysis, the true behavior of the formed radial distributed bus system is achieved and it helps to develop the protection system for this network.

\section{Protection Coordination without DG}

The load flow study and short-circuit analysis gives the overall behavior of the developed radial distribution system and it helps to formed proper protection system for this distribution system. The protection system such as circuit breaker, fuse, re-closer, relay etc. are used to improve the protection coordination of above simulated model. The proper placement of the above protection items optimization program is used using software like MATLAB.

The feeders are protected by overcurrent relays. An inverse time overcurrent protection is used to protect the feeder from overcurrent situation. In the inverse time overcurrent protection, the operating time is inversely proportional to the magnitude of the fault current. There are many standard curves defining the time-current characteristics. For example, Table 3-2 shows the IEC 60255 characteristics curves.

TABLE I. IEC 60255 Standard Relay Characteristic

\begin{tabular}{|l|l|}
\hline Relay Characteristics & Equations (IEC 60255) \\
\hline Standard Inverse (SI) & $\mathbf{t}=T M S * \frac{0.14}{\left(I_{r}\right)^{0.2}-1}$ \\
\hline Very Inverse (VI) & $\mathbf{t}=T M S * \frac{13.5}{\left(I_{r}\right)-1}$ \\
\hline Extremely Inverse (EI) & $\mathbf{t}=T M S * \frac{80}{\left(I_{Y}\right)^{2}-1}$ \\
\hline Long time stand by earth fault & $\mathbf{t}=T M S * \frac{120}{\left(I_{r}\right)-1}$ \\
\hline
\end{tabular}


In this study, the standard inverse characteristic curve is used for the relays. The pickup current of the inverse time overcurrent relay is selected to start at 1.05 to 1.20 times primary currents of the current transformer. The primary currents of the current transformers are selected by considering the maximum load currents. For the time multiplier setting, the value of 0.2 is selected for the IEC normal inverse characteristic curve. As fault current is obtained from the short-circuit analysis, the plug setting multiplier (PSM) is calculated.

$$
P S M=\frac{\text { Fault Current (If) }}{\text { Pickup Current(Is) }}
$$

The operating minimum time delay setting for the instantaneous element is 60 milliseconds for HT side and 40 milliseconds for low voltage side. For standard inverse characteristic curve, the time setting multiplier (TSM) can be obtained from equation 2 .

$$
\mathrm{TMS}=\frac{t *\left((P M S)^{0.2}-1\right)}{0.14}
$$

Fuses have an inverse time-current characteristic that is usually plotted as a log-log curve, which is approximated as a second-order polynomial function. The point of interest in this curve occurs where it approaches a straight line. A linear equation [4] can be used to reduce the calculation task as expressed in equation 3 .

$$
\log (t)=a * \log (I)+b
$$

\section{Integrating DGs}

After the proper coordination of the system distributed generations (DGs) are penetrated at places of the developed model. The level of fault current increases when DGs are connected with distribution network with a subsequent serious effect on the existing coordination of the protective devices. DG interface may be either a transformer or a power electronics device, which is another important factor affecting overall short-circuit level. As a result, the DGs may need to be disconnected from the distribution network at fault condition in order to restore relay coordination on the expense of loss of DG power. In order to solve the misscoordination between protective relays resulting from the connection of DGs to a distribution system optimization technique will be used.

\section{E. Analysis of Protection Coordination with DGs}

Since the fault level and configuration of the bus system changes due to introduction of the distributed generation, the protection coordination the system will be no more effective. Again short-circuit and load flow analysis of the system is done after the penetration of the DGs. The short-circuit analysis determine the magnitude of the fault current at different location or branches due to fault at different part of the distribution system. Comparing these calculated/extracted values against the equipment rating is the first step to ensuring that the power system is safely protected. After determination of short-circuit value, protection coordination study is performed to conclude the optimum characteristics, ratings and settings of the protection devices.

\section{F. Optimization of Protection Coordination}

The output of the above given short-circuit data are put into a table for comparison with the ratings of the protection equipment in the system. Time Setting Multiplier (TMS) and Plug Setting (PS) of relays are minimized by optimizing technique to obtain the optimum coordination. The objective function $(\mathrm{OF})$ is

$$
\operatorname{Min} O F=\sum_{i=1}^{n} \text { ti }
$$

Where $n$, total number of the relays and ti, operating time of the ith relay.

If the calculated short-circuit current at given point exceeds the short-circuit rating of the equipment installed at that point, then the location is flagged as being inadequately protected. The optimization technique is used to determine the optimum location and rating of the protection system equipment to establish the protection coordination of the power system. With the short-current values known and the type of protective device selected, it will be easier to design the exact locations for the protective devices [5]. For this step, a device time-current characteristics (TCC) is needed and computer program ETAP along with MATLAB. It is done by placing the TCC for the plant protective device and then overlying down in subsequent order the TCC of each downstream device. With the placement of each TCC, the range of the lowest to highest short circuit current available at that location is compared. Then the time (cycle) separation of the curves is noted. If the TCCs have the needed separation spaces, then the devices coordinate at that location. Protective devices coordinating at one location do not necessarily coordinate at another [6].

\section{G. Optimization of Protection Coordination}

Protective coordination needs trial and error to accomplish the desired results, because the calculations are guesses containing various assumptions. That's why it requires constant watchfulness when it comes to its arrangement. If an event occurs, ones must inform the protective-coordination individual of every short-circuit event so the operator or engineer may review the effects, to see if the protective devices performed as expected. A properly functioning protective-coordination scheme can offer the utility significant savings by reducing unnecessary downtime.

The protection device coordination problems solution using analytic methods was very time consuming for complex and big size power systems. However, proper selection of relay helped in reducing the convergence time of the relay coordination problem. Application of optimization algorithms for solving the protection devices coordination problems had eliminated the need of break point relays. However, graph theory is used for formulation of the relative sequence matrix for identification of primary/backup relay pairs. The mathematical technique, Artificial intelligence, Genetic algorithm, Fuzzy and Neural network based optimization methods are used for protection coordination of the radial distribution system with different level of penetration of distributed generation [6].

Genetic Algorithm is used for the solution of this complex coordination problem and is also used to optimize the time 
clearing time at given constraints. The constraints for this protection coordination between protective devices is time difference between upstream and downstream element, minimum and maximum time to operation of protective elements, time setting multiplier and plug setting multiplier if the protective overcurrent relay.

\section{RESULT AND DISCUSSION}

The model of IEEE 13 bus radial distribution system is developed in the ETAP software and load flow analysis is done to validate the simulation result with the data provided by the IEEE Distribution System Analysis Subcommittee. Protection elements are added to the system according to results obtained from the load flow analysis of the model. Short-circuit analysis is done to find out the amount of short-circuit current (kA) that can flow through the bus of the system. The result of the short-circuit analysis helps to develop the coordination between the protection elements. The complex protection coordination between protection elements is solved and optimized with the help of Genetic Algorithm (GA) using the MATLAB software. The renewable distributed generation is added to the properly coordinated protection system and the impact on the protection coordination is observed. It is observed that mis-coordination and mal-operation of protection elements occurred after the penetration of distributed generation.

\section{A. Protection System}

The IEEE 13 bus radial distribution system is modified with addition of different loads at different buses and load flow analysis is done in order to discover the current flow in different protection devices. The load flow in each protection devices are noted and rating of such elements is set to avoid mal-operation of the system.

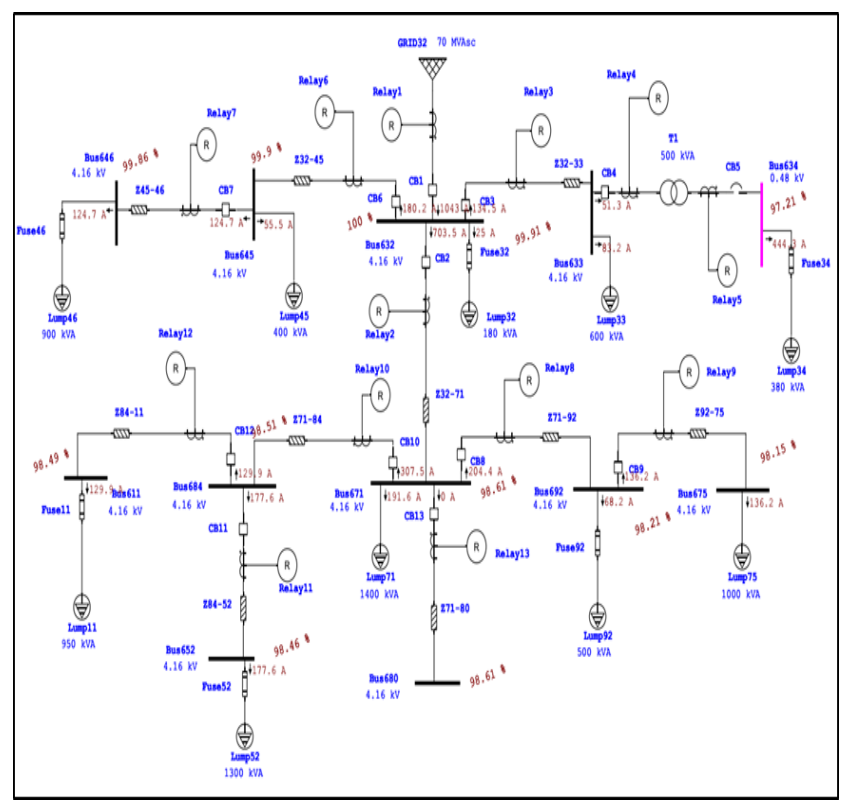

Fig. 2. Load Flow Analysis of modified test system

The short-circuit analysis is done on each of the buses/nodes with the help of Run/Update Short-Circuit kA of star mode toolbar of ETAP software. The result of short-circuit study updated the Time-Current Characteristics
(TCC) clipping current $\mathrm{kA}$ and TCC minimum current $\mathrm{kA}$ of different overcurrent relay.

Table 2 represents the summary of load flow analysis and short-circuit analysis of the test system. The summary of short-circuit of test system shows that fault level at near the source is much higher than the far end of the source.

\begin{tabular}{|c|c|c|c|c|c|}
\hline BUS ID & $\begin{array}{l}\text { Rated } \\
\mathbf{k V}\end{array}$ & $\begin{array}{l}\text { Load } \\
\text { MVA }\end{array}$ & $\% \mathrm{PF}$ & $\begin{array}{l}\text { Full } \\
\text { Load } \\
\text { Current } \\
\text { (Amp) }\end{array}$ & $\begin{array}{l}\text { Symm. } \\
\text { 3-Phase } \\
\text { Fault (kA) }\end{array}$ \\
\hline Bus611 & 4.160 & 921 & 85.0 & 129.9 & 7.72 \\
\hline Bus632 & 4.160 & 7515 & 84.5 & 1043.1 & 9.72 \\
\hline Bus633 & 4.160 & 967 & 84.8 & 134.5 & 9.14 \\
\hline Bus634 & 0.480 & 359 & 85.0 & 444.3 & 13.49 \\
\hline Bus645 & 4.160 & 1297 & 85.0 & 180.2 & 9.32 \\
\hline Bus646 & 4.160 & 897 & 85.0 & 124.7 & 9.09 \\
\hline Bus652 & 4.160 & 1260 & 85.0 & 177.6 & 7.70 \\
\hline Bus671 & 4.160 & 4998 & 84.9 & 703.5 & 7.96 \\
\hline Bus675 & 4.160 & 963 & 85.0 & 136.2 & 6.62 \\
\hline Bus680 & 4.160 & 0 & 0 & 0 & 7.30 \\
\hline Bus684 & 4.160 & 2182 & 85.0 & 307.5 & 7.79 \\
\hline Bus692 & 4.160 & 1446 & 85.0 & 204.4 & 6.73 \\
\hline
\end{tabular}

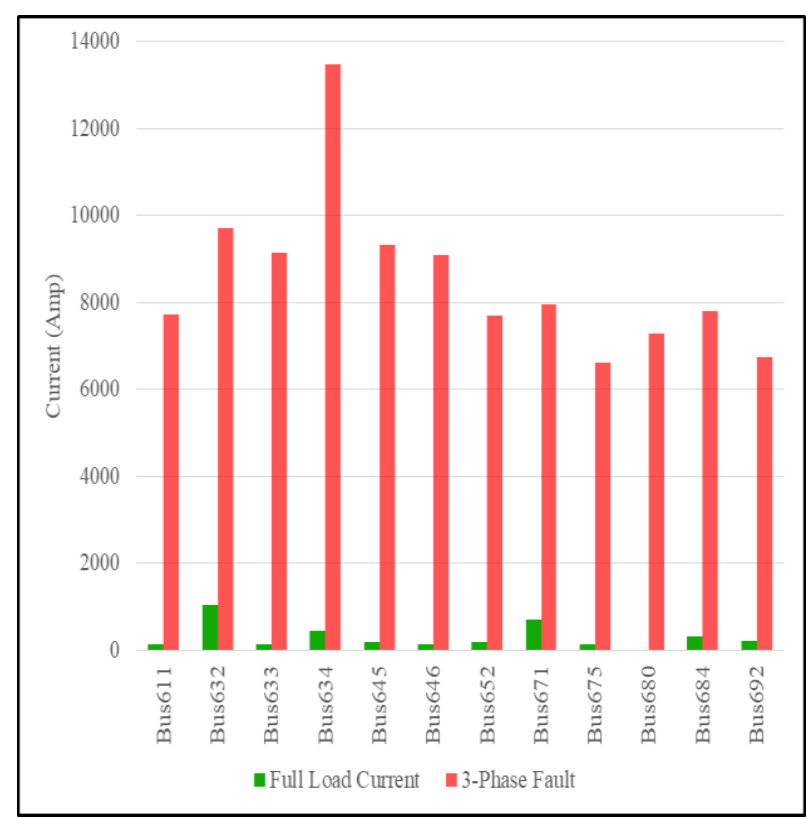

Fig. 3. Full Load Current and Short-Circuit Current

\section{B. Protective Device Coordination}

Time-Current Characteristics (TCC) curve of different protective devices is observed with the help of Star View toolbar of ETAP. The TCC curves of primary and backup protection devices of different element helps to understand the fault clearing Time Difference between devices at particular fault current. The problem of protective devices coordination becomes more complex when the number of branches increases. Genetic Algorithm is used to solve the complex coordination problem which also helps to minimize the final operating time of protective devices. The result of 
optimum time multiplier setting achieved for each relays as a result of genetic algorithm by setting certain plug setting multiplier (PMS) are shown in Table III.

TABLE III. Time setting multiplier obtained from genetic algorith
\begin{tabular}{|c|c|c|}
\hline $\begin{array}{c}\text { Relay } \\
\text { No. }\end{array}$ & $\begin{array}{c}\text { Plug Setting } \\
\text { Multiplier (PMS) }\end{array}$ & $\begin{array}{c}\text { Time Setting } \\
\text { Multiplier (TSM) }\end{array}$ \\
\hline 1 & 0.90 & 0.4032 \\
\hline 2 & 0.90 & 0.2770 \\
\hline 3 & 0.70 & 0.6182 \\
\hline 4 & 0.55 & 0.4151 \\
\hline 5 & 1.00 & 0.0966 \\
\hline 6 & 0.95 & 0.2863 \\
\hline 7 & 0.70 & 0.1236 \\
\hline 8 & 0.75 & 0.2491 \\
\hline 9 & 0.70 & 0.1138 \\
\hline 10 & 0.80 & 0.2339 \\
\hline 11 & 0.95 & 0.1094 \\
\hline 12 & 0.70 & 0.1185 \\
\hline 13 & 1.00 & 0.0939 \\
\hline
\end{tabular}

The optimize solution of time setting multiplier is applied to respective OCRs of the test distribution model and the time current characteristics of the relays obtained as in branch Bus 632 - Bus 634

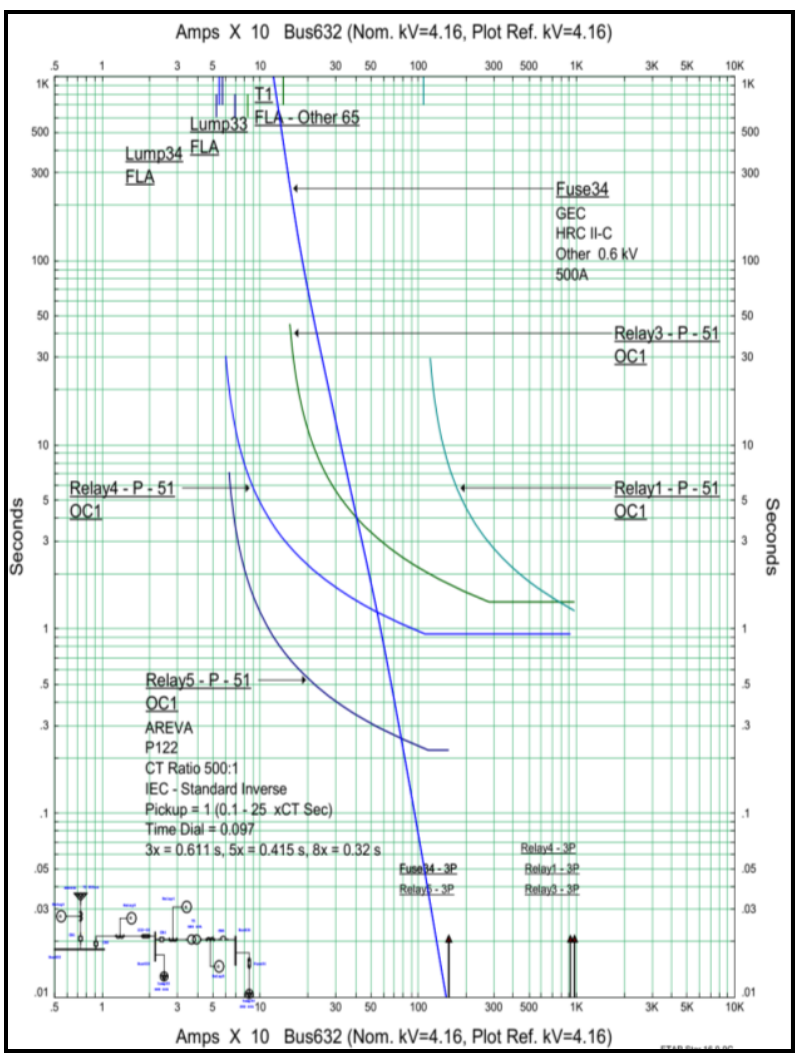

Fig. 4. Star view- TCC of branch Bus 632 to 634

Similarly, the Star view TCC curve of the branch Bus 632 to Bus 611 is shown in figure 5 .

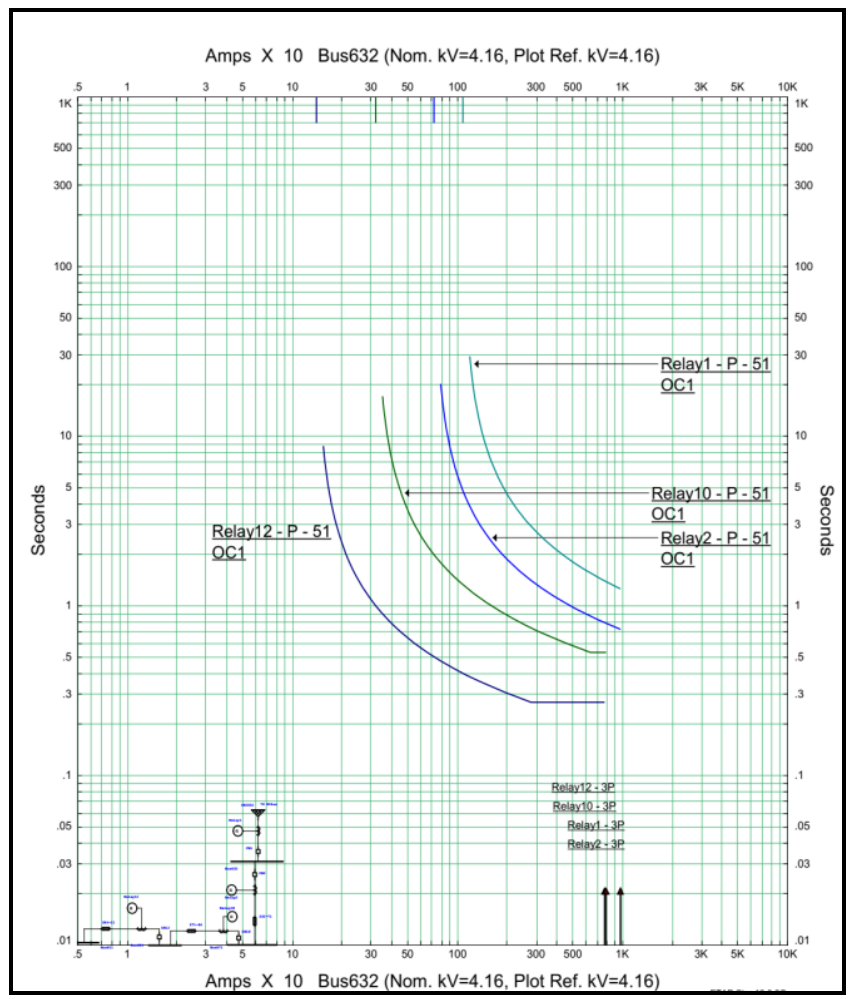

Fig. 5. Star view- TCC of branch Bus 632 to 611

When there is a fault at terminal of load Lump11, the fuse 11 acts as a primary protective device and over current Relay 12 as backup protective device. In case primary and backup protective devices are not operated then Relay 10, Relay 2 and Relay 1 acts as backup protective device sequentially. The figure 6 illustrates the protective device sequence of operation (SQOP) when fault is inserted at terminal of load Lump11.

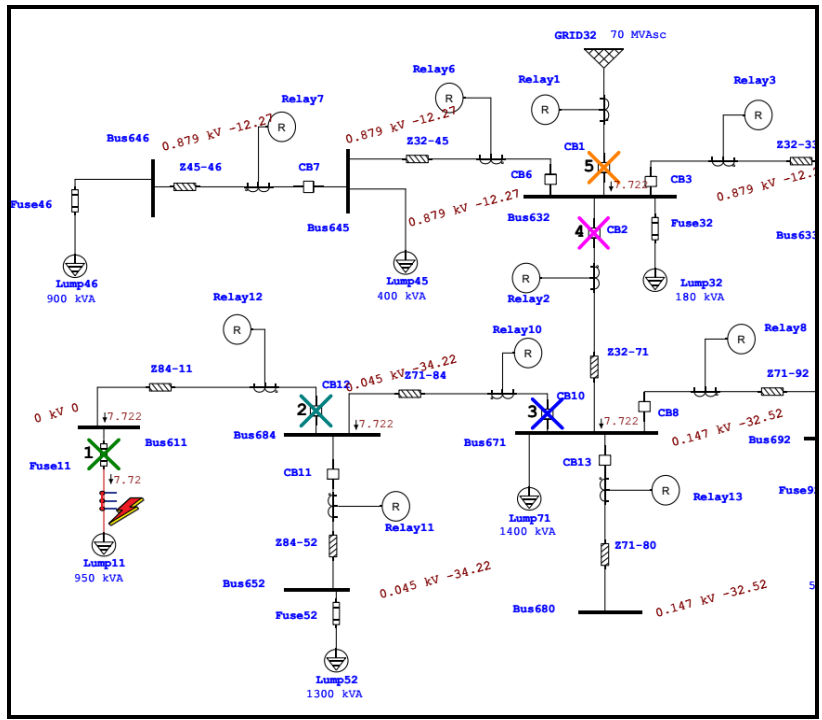

Fig. 6. Sequence of Operation of Protective Devices when fault at Lump11

The figure 7 shows the output report of sequence-of-operation of protective devices with discrimination between upstream and downstream protective devices. From the table IV, it is observed that protective devices are properly coordinated. 


\begin{tabular}{|c|c|c|c|c|c|}
\hline & \multicolumn{5}{|c|}{ 3.Phase (Symmetrical) fault on connector between Fuse 11 \& Lump11. Adjacent bus: Bus 611} \\
\hline & \multicolumn{3}{|c|}{ Data Rev: Base } & Config: Normal & Date: 25.02 .2019 \\
\hline Time [ms] & ID & If $[k A]$ & $T 1$ (ms) & $\mathrm{T} 2$ (ms) & Condition \\
\hline 10.0 & Fuse11 & 7.722 & $<10.0$ & & \\
\hline 270 & Relay12 & 7.722 & 270 & & Phase $\cdot 0 \mathrm{Cl} \cdot 51$ \\
\hline 330 & CB12 & & 60.0 & & Tripped by Relay 12 Phase - 0 C1 - 51 \\
\hline 531 & Relay10 & 7.722 & 531 & & Phase $\cdot 0 \mathrm{0C1} \cdot 51$ \\
\hline 591 & CB10 & & 60.0 & & Tripped by Relay 10 Phase - 0 C1 - 51 \\
\hline 798 & Relay2 & 7.722 & 798 & & Phase - 0 C1- 51 \\
\hline 858 & CB2 & & 60.0 & & Tripped by Relay 2 Phase - 001 - 51 \\
\hline 1406 & Relay1 & 7.722 & 1406 & & Phase - 0 C1- 51 \\
\hline 1466 & CB1 & & 60.0 & & Tripped by Relay 1 Phase - 0 C1 - 51 \\
\hline
\end{tabular}

Fig. 7. Sequence-of -operation events - Output Report

TABLE IV. Coordination between protective devices

\begin{tabular}{|l|l|l|l|l|l|}
\hline \multicolumn{6}{|l|}{$\begin{array}{l}\text { 3- phase fault applied on Lump11 terminal: current of 7.722 kA flows at } 4.16 \mathrm{kV} \\
\text { level }\end{array}$} \\
\begin{tabular}{|l|l|l|l|} 
S. \\
N.
\end{tabular} & Element & $\begin{array}{l}\text { Operatin } \\
\text { g Time } \\
\text { (sec) }\end{array}$ & $\begin{array}{l}\text { Time } \\
\text { difference with } \\
\text { downstream } \\
\text { element }(\mathrm{sec})\end{array}$ & Relation & Remarks \\
\hline 1 & Fuse11 & 0.010 & 0.010 & $\begin{array}{l}\text { First protective } \\
\text { element }\end{array}$ & $\begin{array}{l}\text { Minimum } \\
\text { operating } \\
\text { time }\end{array}$ \\
\hline 2 & Relay12 & 0.270 & 0.260 & Fuse-Relay & $>150 \mathrm{~ms}$ \\
\hline 3 & Relay10 & 0.531 & 0.261 & Relay-Relay & $>250 \mathrm{~ms}$ \\
\hline 4 & Relay2 & 0.798 & 0.267 & Relay-Relay & $>250 \mathrm{~ms}$ \\
\hline 5 & Relay1 & 1.406 & 0.608 & Relay-Relay & $>250 \mathrm{~ms}$ \\
\hline
\end{tabular}

\section{Penetration of Distributed Generation}

The distribution generation is added at the Bus692 and Bus645. The load flow analysis and the short-circuit analysis show that the fault level of the system increases with addition of the distribution generation. When distribution generation is penetrated in the properly coordinated test distribution system, unnecessary tripping of protective device is observed. This causes the healthy region of the network get cut off unnecessarily and the reliability of the system was reduced.

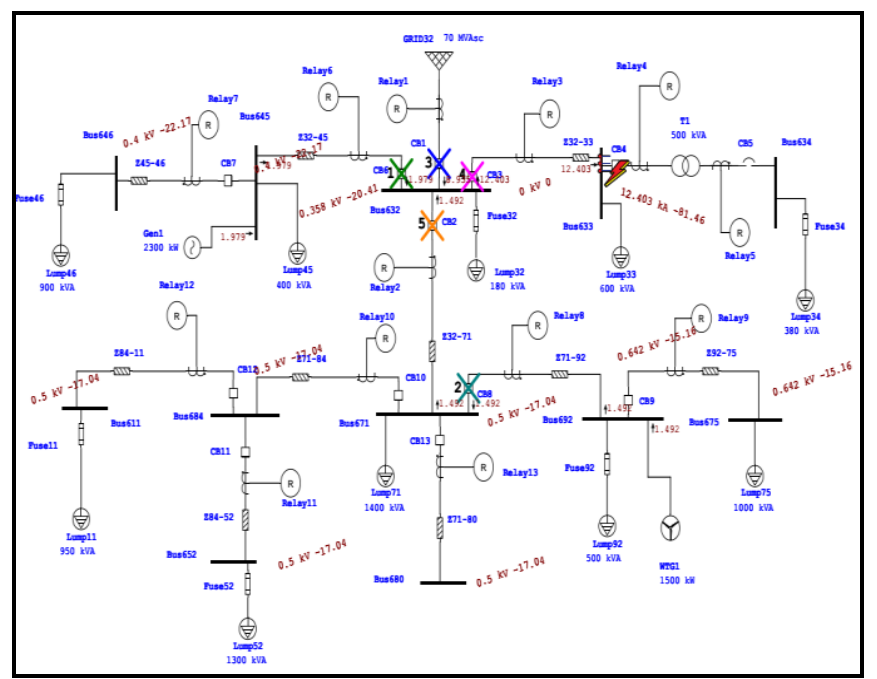

Fig. 8. Sequence of operation of relay when fault at Bus633

The mis-coordination of relay was due to the bidirectional current flow in the system after the penetration of DG. Figure 8 shows the mis-coordination of relay after DG has penetrated in feeder load in the test distribution network.

\section{Protection Coordination after DG Penetration}

After penetration of distributed generation in the test system the mis-coordination of the protective device occur when there is fault in the system. Results show that previously used protective devices were not sufficient for protecting the network after penetration of DG. As a result, additional circuit breaker, current transformer and relays were introduced in the system for proper protection coordination. As the flow of current is bidirectional in some feeder after penetration of DG, directional overcurrent relay was introduced in those feeder. The directional overcurrent relay is necessary for tripping the circuit breaker when the fault current is supplied by distributed generation. The coordination of replay setting is optimized using the genetic algorithm (GA) and the directional overcurrent relay's time setting and plug setting is setup manually. The overcurrent relays trip the circuit breaker when there is fault current from the grid and the directional overcurrent relays trip the circuit breaker when there is fault current provided by the distributed generation.

When there is fault in between the Bus632 and Bus671, sequence of operation of relay occurs as shown in figure 9 which keeps the proper coordination between the protective devices and also directional relay comes into action when there is fault current provided by distributed generation.

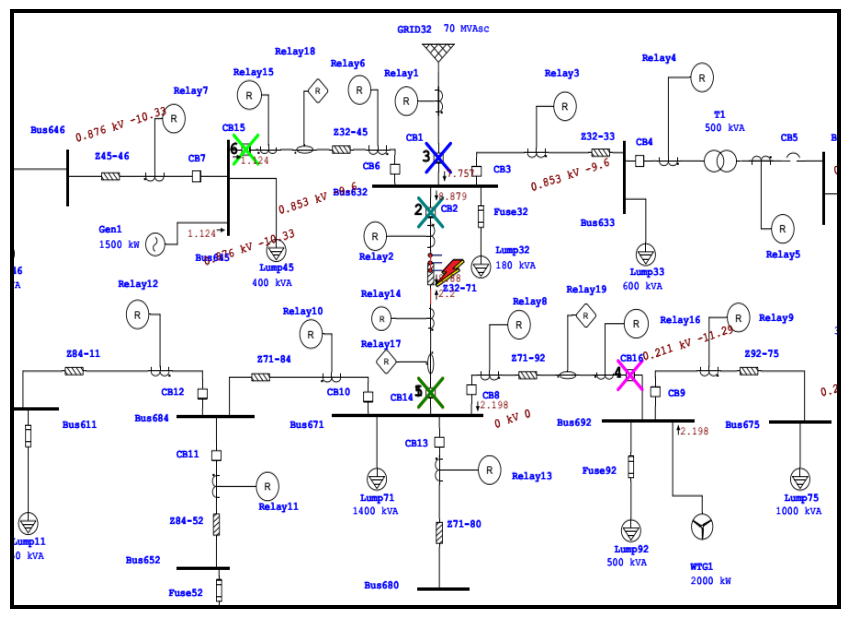

Fig. 9. Sequence of operation of relay when fault is between Bus 632 and 671

The figure 10 shows the output report of sequence-of-operation of protective devices when there is fault at the impedance between the Bus671 and Bus632. The results of sequence-of-operation show the proper coordination between protective devices after penetration of distributed generation in the test system.

\begin{tabular}{|c|c|c|c|c|c|}
\hline \multicolumn{6}{|c|}{ 3.Phase (Symmetrical) fault on connector between CT14 \& Z32.71. Adjacent bus: Bus671 } \\
\hline & \multicolumn{3}{|c|}{ Data Rev: Base } & \multirow{2}{*}{$\begin{array}{c}\text { Config: Normal } \\
T 2 \text { (ms) }\end{array}$} & Date: $30-04-2019$ \\
\hline Time (ms) & ID & If $(\mathrm{kA})$ & $\mathrm{T} 1$ (ms) & & Condition \\
\hline 401 & Relay17 & 2198 & 401 & & Phase - OC1 - 51 - Reverse \\
\hline 421 & CB14 & & 20.0 & & Tripped by Relay 17 Phase - 0C1 - 51 - Reverse \\
\hline 705 & Relay2 & 8.879 & 705 & & Phase - 0C1 - 51 \\
\hline 753 & Relay1 & 7.757 & 753 & & Phase-0C1.51 \\
\hline 765 & $\mathrm{CB} 2$ & & 60.0 & & Tripped by Relay2 Phase - 0C1 - 51 \\
\hline 813 & CB1 & & 60.0 & & Tripped by Relayy Phase - 0C1 - 51 \\
\hline 894 & Relay16 & 2.198 & 894 & & Phase - 0C1-51 \\
\hline 914 & CB16 & & 20.0 & & Tripped by Relay 16 Phase - $0 \mathrm{CC}$ - 51 \\
\hline 945 & Relay14 & 2.198 & $<945$ & & Overload Phase - Thermal \\
\hline 945 & Relay15 & 1.124 & $<945$ & & Overload Phase - Thermal \\
\hline 945 & Relay16 & 2.198 & $<945$ & & Overload Phase - Thermal \\
\hline 965 & CB14 & & 20.0 & & Tripped by Relay 14 Overload Phase - Thermal \\
\hline 965 & CB15 & & 20.0 & & Tripped by Relay15 Overload Phase - Thermal \\
\hline 965 & CB16 & & 20.0 & & Tripped by Rielay16 Overload Phase - Thermal \\
\hline 1043 & Relay17 & 2.198 & $<1043$ & & Overload Phase - Thermal \\
\hline 1063 & CB14 & & 20.0 & & Tripped by Relay 17 Overload Phase - Thermal \\
\hline 1089 & Relay6 & 1.124 & 1089 & & Phase - 0 C1 - 51 \\
\hline 1149 & CBG & & 60.0 & & Tripped by Relay 6 Phase - 0 OC1 - 51 \\
\hline 1158 & Relay8 & 2.198 & 1158 & & Phase - $0 \mathrm{CC1}-51$ \\
\hline 1218 & $\mathrm{CB} 8$ & & 60.0 & & Tripped by Relays Phase - $0 \mathrm{C1}$ - 51 \\
\hline 2213 & Relay14 & 2.198 & 2213 & & Phase - OC1 - 51 \\
\hline 2233 & CB14 & & 20.0 & & Tripped by Relay 14 Phase - OC1 - 51 \\
\hline 2419 & Relay15 & 1.124 & 2419 & & Phase - OC1 - 51 \\
\hline 2439 & CB15 & & 20.0 & & Tripped by Relay15 Phase - 0C1 - 51 \\
\hline
\end{tabular}

Fig. 10. Sequence-of -operation events with DG - Output Report 


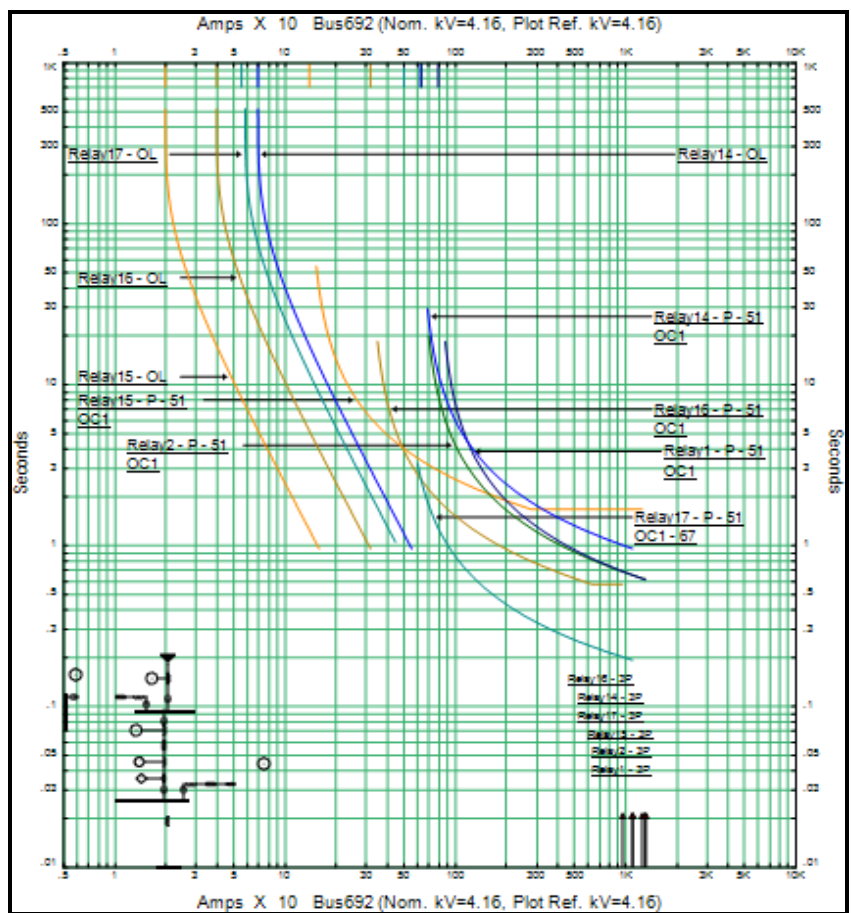

Fig. 11. Star View- Time-Current Characteristics

From the figure 9, 10 and 11, it is observed that protective devices of test system after the penetration of distributed generation are properly coordinated.

\section{CONCLUSION}

A comparative study for protection coordination of protective devices is presented for modified IEEE 13 Bus radial distribution system in presence and absence of distributed generation. The results of the simulation studies show that coordination of the distribution system is altered after the penetration of the distributed generation. The short-circuit analysis shows that the fault level of different buses of the network is altered and fault current of the grid decreases as the additional fault current is provided by the distributed generation. Due to the penetration of the DG bidirectional current flows from the different branches of the distribution network. The proper coordination of protection devices of distribution network after the penetration of distributed generation is important to avoid false tripping and to increase the reliability of the network. This paper has proposed genetic algorithm method to maintain the coordination between the protective devices and the directional relay for reverse fault current contributed by the distributed generation. The proposed method can solve the complexity of the coordination problem caused by the connection of DG.

\section{ACKNOWLEDGMENT}

The authors extend their hearty gratitude to the faculties and colleagues at Tribhuvan University, Institute of Engineering, Pulchowk Campus for their constant help, support and recommendations. The authors would also like to thank Er. Jitendra Thapa, Er. Raghbendra Kumar Jha and Er. Meghnath Bhattrai for their supports.

\section{REFERENCES}

[1] H. Zayandehroodi, A. Mohamed, H. Shareef and M. Mohammadjafari, "Impact of distributed generations on power system," International Journal of the Physical Sciences, vol. 6(16), pp. 3999-4007, 2011.

[2] A. Huda and R. Živanović, "Large-scale integration of distributed generation into distribution networks: Study objectives, review of models and computational tools," Renewable and Sustainable Energy Reviews, no. 76, pp. 974-988, 2017.

[3] The Institute of Electrical and Electronics Engineers, Inc., "IEEE 13 Node Test Feeder," IEEE Power Engineering Society.

[4] J. Wafi, S. M. Saad, K. E.-A. Naser El Naily and F. A. Mohamed, "Applicability Analysis of Proactive RecloserFuse Scheme for Wind Distributed Generation Into Modern Distribution Network," The 9th International Renewable Energy Congress (IREC 2018), no. 9, p. 6, 2018.

[5] H. A. Abdel-Ghany, A. M. Azmy, N. I. Elkalashy and E. M. Rashad, "Optimizing DG penetration in distribution networks concerning protection schemes and technical impact," Electric Power Systems Research, vol. 128, pp. 113-112, 2015.

[6] M. Singh, "Protection coordination in distribution systems with and without distributed energy resources- a review," Protection and Control of Modern Power Systems, vol. 2, p. 17, 2017.

[7] E. Nsengiyumva, "Impact of DG Integration on Overcurrent protective relays in Distribution Networks," International Journal of Multidisciplinary Innovative Research, vol. I, no. 3, pp. 1-8, 2018. 